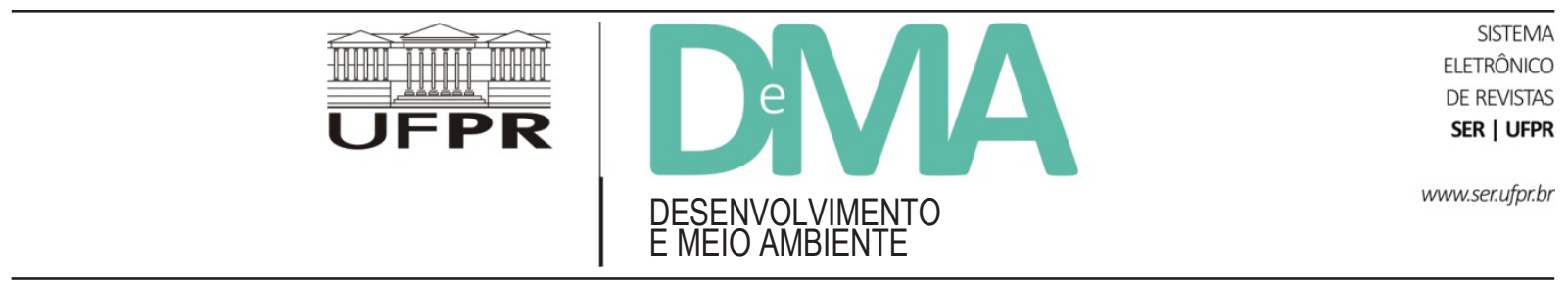

\title{
Uso de recursos madeireiros em duas comunidades rurais de Angical do Piauí/PI, Brasil
}

\section{Use of Wood Resources in Two Rural Communities of Angical do Piauí/PI, Brazil}

\author{
Irineu Campêlo da FONSECA FILHO ${ }^{1,2^{*}}$, Brunna Laryelle Silva BOMFIM ${ }^{1,2}$, Juliana Cardozo de FARIAS ${ }^{1}$, \\ Fábio José VIEIRA ${ }^{3}$, Roseli Farias Melo de BARROS ${ }^{1}$ \\ ${ }^{1}$ Programa de Pós-Graduação em Desenvolvimento e Meio Ambiente (MDMA), Universidade Federal do Piauí (UFPI), Teresina, PI, Brasil. \\ ${ }^{2}$ Instituto Federal do Piauí (IFPI), Teresina, PI, Brasil. \\ ${ }^{3}$ Universidade Estadual do Piauí (UESPI), Picos, PI, Brasil. \\ *E-mail de contato: irineu.campelo@ifpi.edu.br
}

Artigo recebido em 19 de dezembro de 2015, versão final aceita em 3 de agosto de 2016.

RESUMO: As populações rurais se utilizam de espécies vegetais para as mais diversas finalidades. De acordo com a forma de extração e a parte utilizada da planta, o uso madeireiro pode trazer danos ambientais, como o desmatamento de florestas, bem como acarretar risco de extinção de determinadas espécies. Objetivou-se avaliar o conhecimento, a preferência e o uso madeireiro nas comunidades rurais Chapada do Hamilton e Novo Horizonte, município de Angical do Piauí/PI. Foram realizadas entrevistas semiestruturadas com 27 chefes de famílias residentes nas comunidades, além do emprego da técnica de inventário in situ. No total foram encontradas 62 espécies identificadas, distribuídas em 28 famílias, utilizadas nas categorias de uso construção, tecnologia e fitocombustível. Em relação à riqueza de espécies citadas, a comunidade Chapada do Hamilton apresentou o maior número de espécies conhecidas. Não foi encontrada diferença estatística entre o número de espécies conhecidas, usadas e preferidas entre as comunidades nas três categorias analisadas. A categoria construção apresentou o maior número de espécies citadas no total, com 55 espécies, em comparação com as categorias tecnologia e fitocombustível, com 40 e 28 espécies citadas, respectivamente. Comparando as categorias de uso em relação ao número de espécies citadas nas duas comunidades, verificaram-se diferenças estatísticas entre as categorias construção e fitocombustível, o que não se repetiu entre as categorias construção e tecnologia e tecnologia e fitocombustível. Os usos específicos na categoria fitocombustível ocorrem, predominantemente, na forma de carvão. Foi verificado que as populações de ambas as comunidades conhecem ampla diversidade de espécies fornecedoras de madeira e sugere-se que seja dada prioridade, em futuras estratégias de conservação, para espécies que possuem preferência em mais de uma categoria de uso.

Palavras-chave: tecnologias; fitocombustível; plantas lenhosas; construções rurais; cerrado. 
ABSTRACT: Rural populations use many plant species for different purposes. According to form of extraction and used part of the plant, the wood use can bring environmental damage such as deforestation and cause extinction of certain species. This study aims to evaluate the knowledge, preference and timber use in the rural communities of Chapada Hamilton and Novo Horizonte in the Angical municipality of Piauí/PI. Semi-structured interviews were conducted with 27 heads of families living in communities, besides the use of inventory in situ. There were found 62 identified species in total, belonging to 28 different wood families, used in the categories of building, technology and phyto fuel. Regarding the richness of the species mentioned Chapada do Hamilton's community had the largest number of known species. There was no statistical difference between the number of known species, used and preferred among communities in the three categories analyzed. Construction had most of the species mentioned in total, with 55 species in comparison with the categories technology and phyto fuel, 40 and 28 of the mentioned species, respectively. Comparing the categories of use against the number of species mentioned in the two communities, there were statistical differences between Building and Phyto fuel, which were not repeated in the categories construction and technology and phyto fuel technology. The specific use in phyto fuel category occurs predominantly in the form of coal. It was observed that populations of both communities know a wide variety of species of wood, and it is suggested that priority be given in future maintenance strategies to species which have preference in more than one category of use.

Keywords: technology; phyto fuel; woody plants; rural construction; Cerrado (Brazilian Vegetation).

\section{Introdução}

O uso de recursos naturais sempre esteve presente no cotidiano do homem, que utiliza os bens da natureza para prover alimento, remédios, vestimentas, por exemplo. Dentre esses usos, destaca-se a extração de madeira para fins domésticos, em que é utilizada para atender as necessidades das populações locais, tais como construção de cercas para delimitação de terrenos, confecção de ferramentas de trabalho, uso como fonte de energia e construção de casas (Gaugris et al., 2006; Ramos et al., 2008; Chaves et al., 2014).

Devido à intensa utilização de recursos madeireiros em algumas comunidades, espécies vegetais podem ter sua população reduzida drasticamente e apresentar risco de extinção local. Estudo em Uganda constatou que populações de espécies lenhosas apresentaram declínio, principalmente devido à extração para produção de carvão e postes de madeira (Tabuti, 2012). Samant et al. (2000) e Kristensen e Lykke (2003) também afirmaram que as populações aproveitam amplo conjunto de espécies para fins madeireiros, mas existem grupos de espécies que são preferidas pelas comunidades e consequentemente sofrem maior pressão extrativista.

$\mathrm{O}$ uso de recursos madeireiros para fins domésticos tem ocupado grande espaço nos países em desenvolvimento, por isso, a maior parte dos estudos relativos a esses usos tem sido concentrada em países da América Latina, da África e da Ásia (Tabuti et al., 2003; Walters, 2005; Gaugris et al., 2006; Ramos et al., 2008; Vieira, 2014). Análises estruturais e de composição das habitações de uso doméstico em comunidades rurais da África do Sul, por exemplo, mostraram preferência de paredes de madeira e argila na construção das residências (Gaugris et al., 2006). Na China, estudo aponta que problemas causados devido à escassez de recursos madeireiros não são recentes. Em 1998, o governo chinês lançou o Programa de Proteção Florestal Natural (PPFN) com o objetivo de proibir a extração de certas espécies vegetais lenhosas e limitar a extração de outras. Com a diminuição da extração de madeira e o aumento da demanda devido ao crescimento da população chinesa, a solução en- 
contrada foi a importação de madeira. Pesquisas apontam que a importação de madeira continuará a ser a principal forma de abastecimento de madeira doméstica na China (Yang et al., 2010). Diversos trabalhos realizados em vários países também apresentaram usos de espécies lenhosas, bem como as consequências da extração indiscriminada, tais como os realizados por Depro et al. (2008), Guariguata et al. (2008), Nelson et al. (2009), Pulhin \& Dressler (2009), Guariguata et al. (2010), Leefers e Vasievich (2010), Nasi et al. (2012), Silva et al. (2012) e Robiglio et al. (2013).

Sabendo-se que ainda há muito o que se conhecer sobre a biodiversidade brasileira (Garay \& Becker, 2006) e cientes da estreita relação que existe entre o conhecimento das populações tradicionais e a biodiversidade local, reconhecemos a necessidade da realização de estudos etnobiológicos no país, abrangendo comunidades rurais e que objetivem mensurar a diversidade biológica e entender a relação histórica entre pessoas e natureza que levaram à conservação das áreas onde residem.

Objetivou-se identificar as espécies utilizadas como fonte de recursos madeireiros, destacando as características mais apreciadas nas espécies e relacionar as espécies conhecidas, preferidas e mais utilizadas para tais fins nas comunidades Chapada do Hamilton e Novo Horizonte, Município de Angical do Piauí, PI, Brasil. O presente estudo se baseou nos seguintes questionamentos: há diferença entre o número de espécies utilizadas entre as comunidades estudadas? Há diferença entre a quantidade de espécies conhecidas, usadas e preferidas dentro das comunidades estudadas? Qual das categorias de uso madeireiro apresenta maior diversidade de espécies conhecidas? Quais as características utilizadas para seleção de espécies para usos madeireiros nas diferentes categorias de uso? Há relação entre as espécies preferidas e o valor de uso? Diante disso, são lançadas as seguintes hipóteses: (H1) o número de espécies utilizadas para fins madeireiros varia entre as comunidades; (H2) a população conhece número elevado de espécies de uso madeireiro, porém, usa quantidade menor de espécies e prefere quantidade menor ainda; (H3) há diferenças entre o número de espécies conhecidas entre as categorias, sendo que a categoria construção apresenta o maior número de espécies citadas; (H4) as características utilizadas para seleção de espécies preferidas são diferentes entre as categorias; (H5) as espécies citadas como preferidas terão maior valor de uso.

\section{Metodologia}

\section{1. Área de estudo}

O município de Angical do Piauí está localizado na microrregião do Médio Parnaíba Piauiense, a $192 \mathrm{~m}$ acima do nível do mar, distante $120 \mathrm{~km}$ da capital Teresina, PI. Possui 6.772 habitantes, segundo o censo do IBGE (2010), sendo que $21,53 \%$ da população residem na zona rural.

Apresenta temperatura média que varia entre $20^{\circ} \mathrm{C}$ e $30^{\circ} \mathrm{C}$ e clima quente tropical. A precipitação pluviométrica média anual (com registro de 1.200 $\mathrm{mm}$, na sede do município) é definida no Regime Equatorial Continental, com isoietas anuais entre 800 a $1.400 \mathrm{~mm}$, cerca de 5 a 6 meses como os mais chuvosos e período restante do ano de estação seca. Os meses de janeiro, fevereiro e março correspondem ao trimestre mais úmido. Os solos da região são provenientes da alteração de arenitos, siltitos, folhelhos, silexitos, calcários e argilitos. Compreendem solos litólicos, álicos e distróficos, de textura média, pouco desenvolvidos, rasos a muito rasos, fase pedregosa, com floresta caducifólia e/ou floresta subcaducifólia/cerrado (Aguiar \& Gomes, 2004). 
O estudo foi realizado nas comunidades Chapada do Hamilton e Novo Horizonte (Figura 1). De acordo com os agentes de saúde do município, a comunidade Chapada do Hamilton é composta por 12 famílias, sendo uma das comunidades mais recentes de Angical do Piauí, e dista $18 \mathrm{~km}$ do centro municipal. $\mathrm{O}$ assentamento foi fundado em 2002 por meio do Projeto de Combate à Pobreza Rural (PCPR), cujo objetivo era contribuir para o alívio da pobreza rural. Inicialmente, o projeto de criação do assentamento contemplava 19 famílias. $\mathrm{Na}$ execução da pesquisa, foram encontradas 11 famílias residentes na comunidade, enquanto oito famílias do projeto inicial do assentamento não residem mais na comunidade.
A comunidade Novo Horizonte é uma das mais antigas e dista cerca de $12 \mathrm{~km}$ do centro do município e aproximadamente $20 \mathrm{~km}$ da comunidade Chapada do Hamilton. Inicialmente, a comunidade possuía 45 famílias residentes, mas, devido à criação do assentamento Novo Horizonte, muitas famílias saíram da comunidade. Devido a alguns problemas de estrutura, de acordo com os entrevistados, algumas famílias retornaram para a comunidade Novo Horizonte, sendo que no momento da pesquisa, segundo o agente de saúde local, a comunidade possuía 22 famílias residentes.

A escolha das comunidades foi feita levando em consideração a distância da cidade, com o intuito de verificar a influência da proximidade do centro

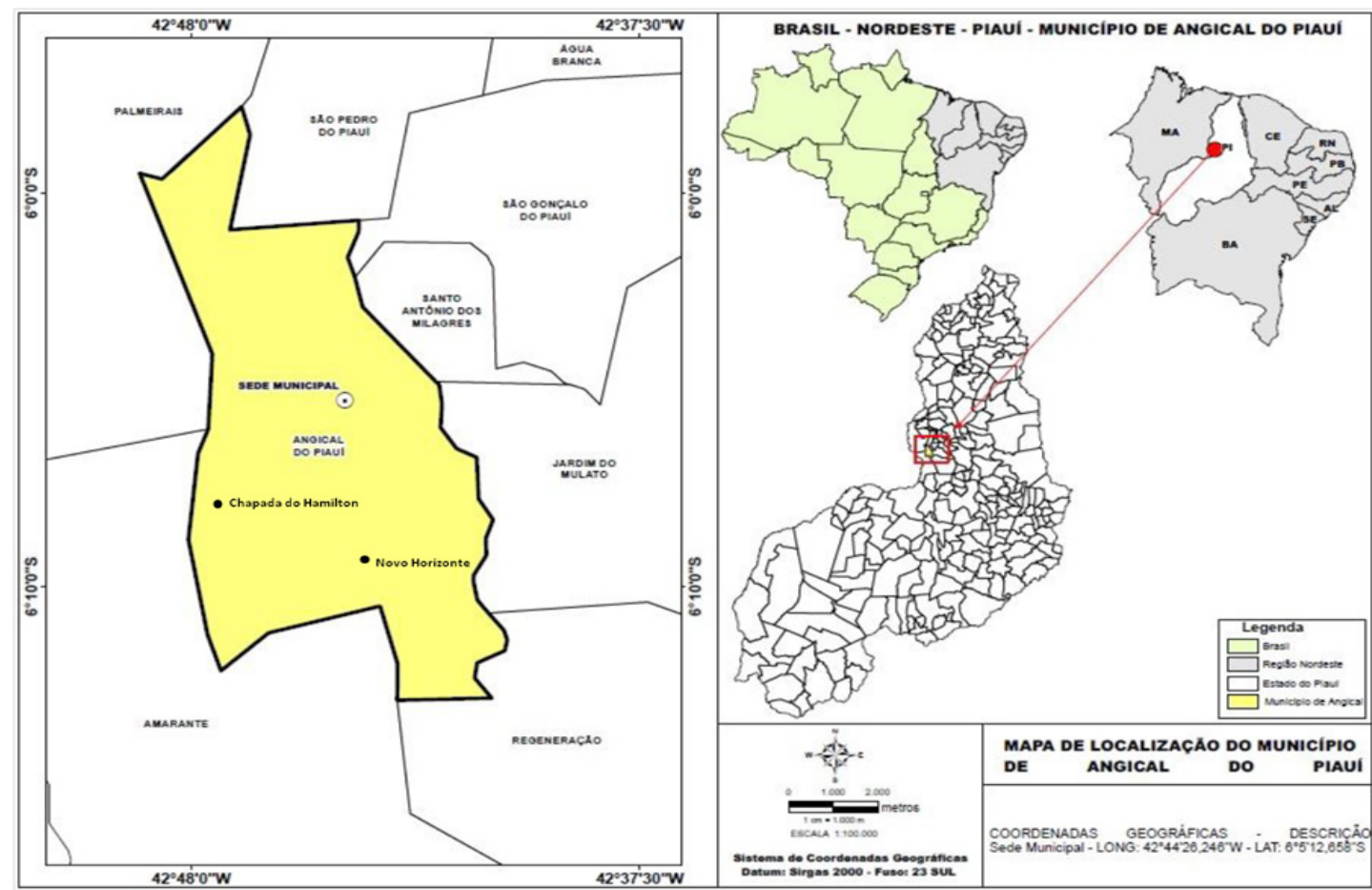

FIGURA 1 - Localização do município de Angical do Piauí/PI, destacando as comunidades rurais Chapada do Hamilton e Novo Horizonte. FONTE: IBGE (2010), modificado por Celso Leite. 
urbano no conhecimento e no uso de recursos madeireiros, comparando os conhecimentos entre os indivíduos das comunidades selecionadas.

\subsection{Coleta e análise dos dados}

Por se tratar de pesquisas envolvendo seres humanos, este trabalho foi primeiramente encaminhado ao Conselho de Ética em Pesquisa (CEP), sendo aprovado sob o número CAAE: 42826815.2.0000.5214. Antes de cada entrevista, foi solicitada a permissão do entrevistado por meio da assinatura do Termo de Consentimento Livre e Esclarecido (TCLE), em conformidade ao que rege a Resolução no 466/2012 do Conselho Nacional de Saúde.

No início da pesquisa, foi adotada a técnica de rapport (Barbosa, 2007), na qual o pesquisador realiza visitas prévias, participando do cotidiano da comunidade e realizando reuniões para explicar o trabalho, com a finalidade de criar uma ligação de sintonia, empatia e confiança com os moradores das comunidades.

O universo amostral foi selecionado de acordo com o proposto por Almeida e Albuquerque (2002) e Tongco (2007), sendo entrevistados em cada comunidade todos os chefes de famílias e/ou os responsáveis pela coleta de madeira.

As entrevistas semiestruturadas foram realizadas com auxílio de formulários padronizados que continham questões abertas e fechadas, visando levantar os dados socioeconômicos dos moradores das comunidades e informações sobre o uso, o conhecimento, as preferências e a coleta de plantas da região, além do emprego da técnica da lista livre, com o objetivo de verificar as plantas conhecidas e/ou utilizadas para fins madeireiros. A constatação do uso efetivo das espécies citadas foi realizada por meio da técnica de inventário in situ (Ramos; Medeiros \& Albuquerque, 2010), em que as espécies e as categorias de uso presentes nas residências no momento da visita foram registradas. Foi analisada, além dos estoques de madeira disponíveis, também a madeira utilizada nas diferentes categorias em todos os domicílios visitados. Quando possível, foram solicitadas ao responsável pela residência informações acerca da identidade do material madeireiro encontrado, permitindo, assim, obter a frequência das espécies nas categorias de uso nas residências.

Visando proceder às coletas das espécies, bem como para identificar os nomes vernaculares das plantas e seus respectivos atributos, realizaram-se turnês guiadas (Bernard, 1988), de modo a validar e fundamentar os nomes mencionados durante as entrevistas (Albuquerque et al., 2014).

Para coleta e herborização das espécies vegetais citadas, seguiu-se técnica usual (Mori et al., 1989; Fidalgo \& Bononi, 1989). A identificação botânica foi realizada mediante análises morfológicas (comparações com materiais incorporados ao acervo do TEPB) e confirmada por especialistas. Foi adotado como sistema de classificação o APG IV (2016). As espécies coletadas foram incorporadas ao Herbário Graziela Barroso (TEPB), da Universidade Federal do Piauí (UFPI). A conferência da grafia das espécies e a abreviatura do nome dos autores se deu por meio do sítio do MOBOT (2016).

Após as coletas dos dados, as espécies foram agrupadas em categorias de uso de acordo com as informações prestadas pelos entrevistados.

Como técnica de análise quantitativa utilizou-se o Valor de Uso (VU), por meio da fórmula VU = $\Sigma \mathrm{u} / \mathrm{n}$, em que $\mathrm{u}=$ número de citações da espécie por informante e $\mathrm{n}=$ número de informantes (Phillips \& Gentry, 1993), modificada por Rossato (1996), em que o pesquisador assume que as espécies com o maior valor são as mais importantes para comunida- 
de. Foi aplicado o Teste Não Paramétrico de Wilcoxon para verificar diferenças entre o conhecimento e o uso de plantas para fins madeireiros entre as comunidades, bem como diferenças entre o número de espécies conhecidas e usadas. As frequências de conhecimento, de uso e de preferência das espécies utilizadas com fins madeireiros foram calculadas por meio da razão entre o número de informantes que conhecem/usam/preferem determinada espécie pelo número total de informantes entrevistados que citaram alguma espécie que conhecem/usam/ preferem em cada comunidade. Diferenças no número de espécies conhecidas e preferidas entre as duas comunidades foram avaliadas por meio do teste do Qui-quadrado. Todos os testes foram executados utilizando o software BioEstat 5.0 (Ayres et al., 2007).

\section{Resultados e discussão}

\subsection{Espécies conhecidas, usadas e preferidas nas categorias de uso}

Nas duas comunidades foram citadas 75 plantas, contabilizando, até o presente, 62 espécies identificadas, distribuídas em 28 famílias, utilizadas nas categorias de uso construção, tecnologia e fitocombustível. Verificou-se destaque para as famílias Fabaceae (22), Anacardiaceae, Arecaceae, Bignoniaceae e Combretaceae (4). A família Fabaceae se destaca no número de espécies em muitos estudos e, como exemplos, têm-se: Medeiros et al. (2011), com 13 espécies, Nascimento (2013), com 17 espécies, Cavalcanti et al. (2015), com 10 espécies. Também Specht et al. (2015) citou 17 espécies e na investigação de Vieira (2014) foram referidas 24 espécies. Essa predominância pode ser explicada devido à família ser muito frequente na fitofisionomia estudada (Pinto et al., 2009), e ser uma das famílias botânicas mais diversificadas e habitualmente registrada como uma das mais importantes em áreas de cerrado (Carvalho et al., 2008).

Não foi encontrada diferença estatística significativa entre o número de espécies conhecidas, usadas e preferidas entre as comunidades nas três categorias analisadas $(Z=1,4832 ; p=0,1380)$.

Comparando as categorias de uso em relação ao número de espécies citadas nas duas comunidades, verificaram-se diferenças estatísticas significativas entre as categorias construção e fitocombustí$\operatorname{vel}\left(\chi^{2}=8,78 ; p=0,004\right)$, o que não se repetiu entre as categorias construção e tecnologia $\left(\chi^{2}=2,36 ; p\right.$ $=0,15)$ e tecnologia e fitocombustível $\left(\chi^{2}=2,11\right.$; $\mathrm{p}=0,18)$. Contudo, a categoria construção apresentou maior número de espécies citadas no total (55), em comparação com as categorias tecnologia e fitocombustível (40 e 28 , respectivamente). O elevado número de espécies conhecidas, usadas e preferidas dentro de uma categoria pode contribuir para melhor distribuição do impacto da extração de madeira entre as espécies. Categorias de uso com menos espécies tendem a concentrar o impacto da extração em menor número de espécies, tornando-se, assim, mais impactantes nas populações vegetais. Além disso, espécies preferidas podem vir a sofrer maior pressão de coleta (Cavalcanti et al., 2015) e tal fato pode contribuir na modificação das populações vegetais de espécies preferidas nessas categorias ao longo do tempo (Tunholi et al., 2013). Depreende-se parcialmente, portanto, que a categoria construção, por apresentar mais espécies citadas, apresenta o impacto de extração mais distribuído entre as espécies. Contudo, é importante salientar que se fazem necessários mais estudos que contemplem tanto aspectos quantitativos de uso da madeira quanto os fitossociológicos que permitam 
averiguar com mais propriedade os impactos dessa extração no ambiente.

Apesar de não haver diferenças estatísticas significativas em relação ao número de espécies conhecidas, usadas e preferidas, pode-se perceber que, na Chapada do Hamilton, a comunidade que foi fundada há apenas 13 anos apresentou número maior de espécies vegetais utilizadas nas três categorias (59). A comunidade Novo Horizonte, apesar de ser mais antiga e de possuir mais famílias residentes, citou 52 plantas para as referidas categorias (Tabela 1). Da mesma forma, Vieira (2014) realizou estudo comparativo em duas comunidades e verificou o inverso: a comunidade mais antiga apresentou maior acervo de plantas conhecidas, usadas e preferidas em relação à comunidade com menor tempo de fundação, que apresentou menor número de plantas nas três categorias. Outros fatores, que não a idade da comunidade, podem explicar essa diferença no conhecimento de espécies para o fornecimento de recursos madeireiros, como, por exemplo, a distância para o centro urbano, visto que a comunidade Chapada do Hamilton é mais distante (18km) em relação à comunidade Novo Horizonte (12 km). Maior distância do centro urbano, aliada ao baixo poder aquisitivo, como pôde ser verificado nos dados socioeconômicos das entrevistas, em que 55\% dos moradores do assentamento Chapada do Hamilton têm renda menor que um salário mínimo e $90 \%$ dos moradores da comunidade Novo Horizonte tem renda de um salário mínimo, podem dificultar o acesso a determinados recursos, como gás de cozinha e madeira serrada, por exemplo, incentivando assim uma busca maior por recursos do ambiente para suprir tais necessidades, podendo resultar em maior conhecimento de espécies vegetais.

Outro fator que deve ser levado em consideração é que os moradores da comunidade Chapada do Hamilton, em virtude de se tratar de assentamento, possuem origens diversificadas, sendo a maioria oriunda do próprio município de Angical e de municípios circunvizinhos. A população provinda de diferentes realidades culturais e ambientais, quando reunida em um só local, pode contribuir para incrementar o conhecimento das espécies vegetais, pois, de acordo com Medeiros et al. (2011), em estudo sobre o conhecimento de plantas medicinais de comunidades migrantes, a necessidade de substituição de algumas plantas que não são encontradas no novo local acaba aumentando o leque de espécies utilizadas para determinado fim. Já Vieira (2014), trabalhando com fitocombustíveis numa comunidade quilombola e em assentamento, verificou que o assentamento apresentou uma quantidade menor de espécies conhecidas em relação à comunidade quilombola, ressaltando que isso pode acontecer devido ao tempo em que os moradores estão em contato com a vegetação local.

\subsection{Categorias de uso}

\subsubsection{Construção}

O uso de madeira para a categoria construção esteve presente em todas as residências visitadas, sendo constatadas duas subcategorias, conforme Lucena et al. (2011): construções rurais (cercas, currais e canteiros) e domésticas (telhados e paredes) (Figuras 2 e 3). Construções semelhantes foram listadas no trabalho de Chaves et al. (2014), realizado em vegetação de carrasco na Área de Proteção da Serra da Ibiapaba, que levantou o conhecimento tradicional na construção de cercas, encontrando Aspidosperma pyrifolium Mart. e Cedrela odorata L. como espécies mais importantes, e Silva \& Barros (2015), que objetivaram conhecer os vegetais utilizados nas construções rurais em área de caatinga, onde a espécie em destaque foi o marmeleiro (Croton blanchetianus Baill). 


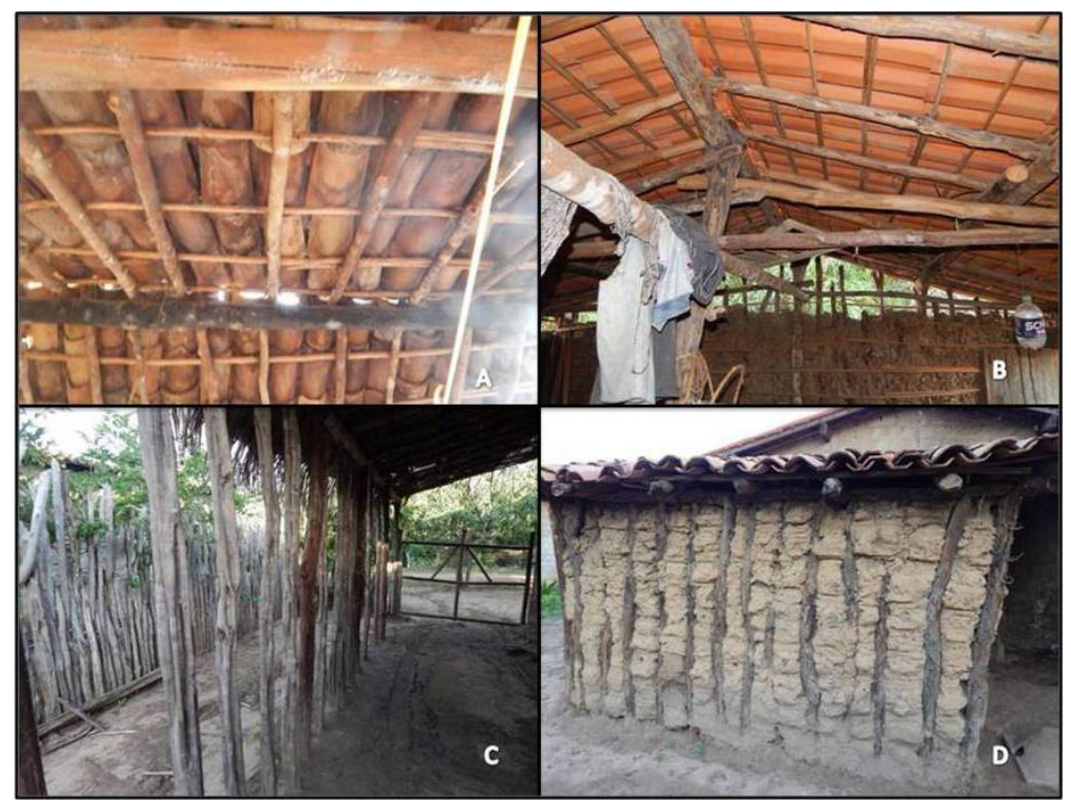

FIGURA 2 - Construções domésticas encontradas nas comunidades Chapada do Hamilton e Novo Horizonte, Angical do Piauí/PI. A e B - Telhados; C - Garagem; D - Parede. FONTE: arquivo pessoal.

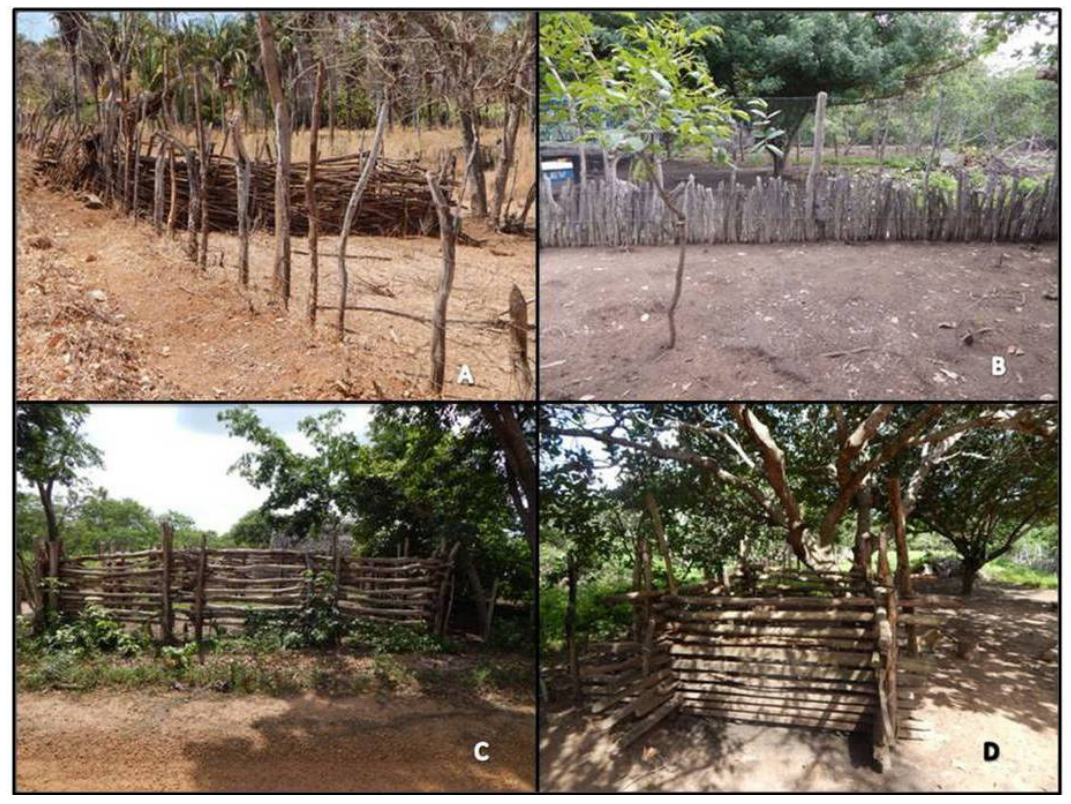

FIGURA 3 - Construções rurais presentes nas comunidades Chapada do Hamilton e Novo Horizonte, Angical do Piauí/PI. A e B - Cercas; C - Curral; D - Chiqueiro. FONTE: arquivo pessoal. 


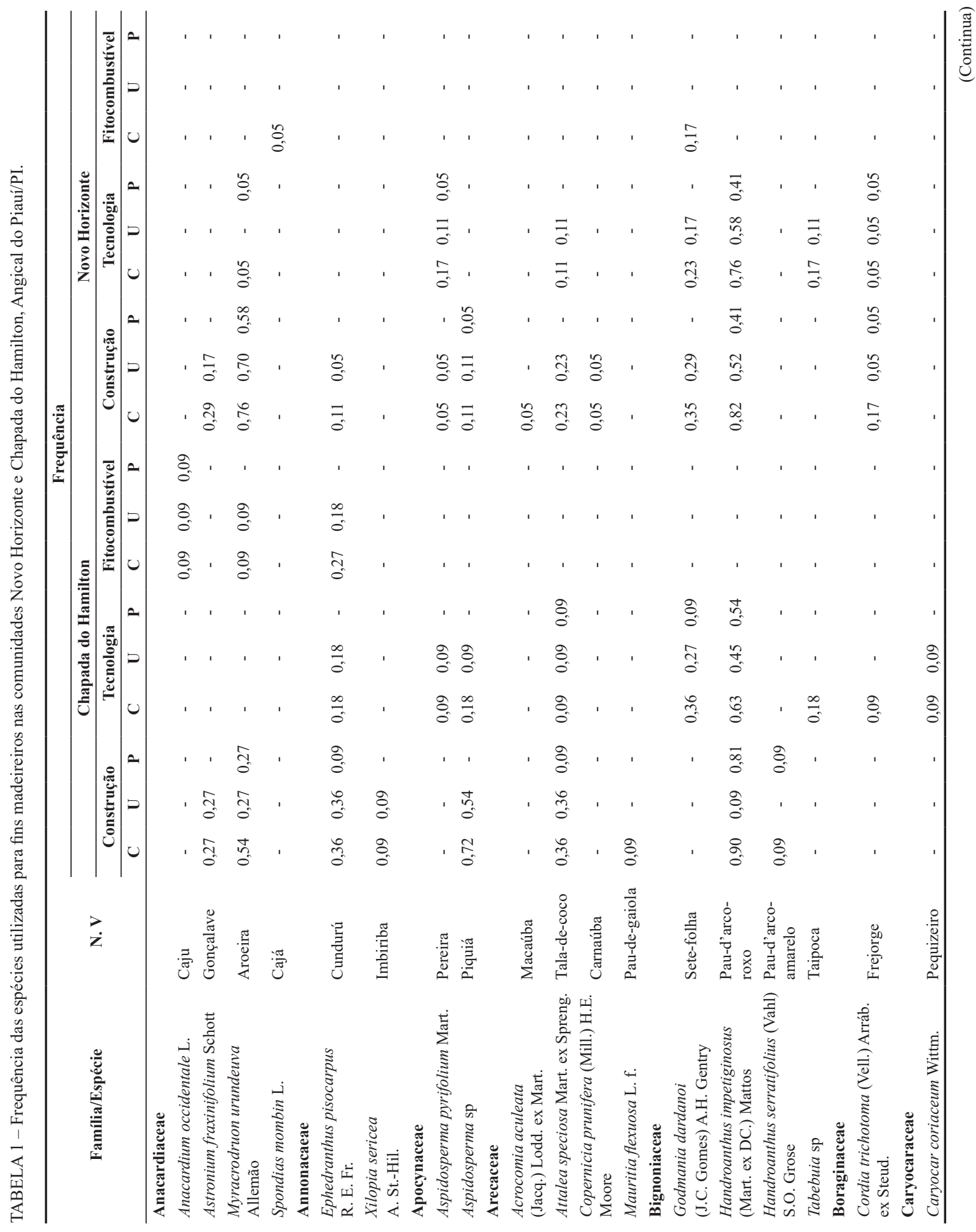




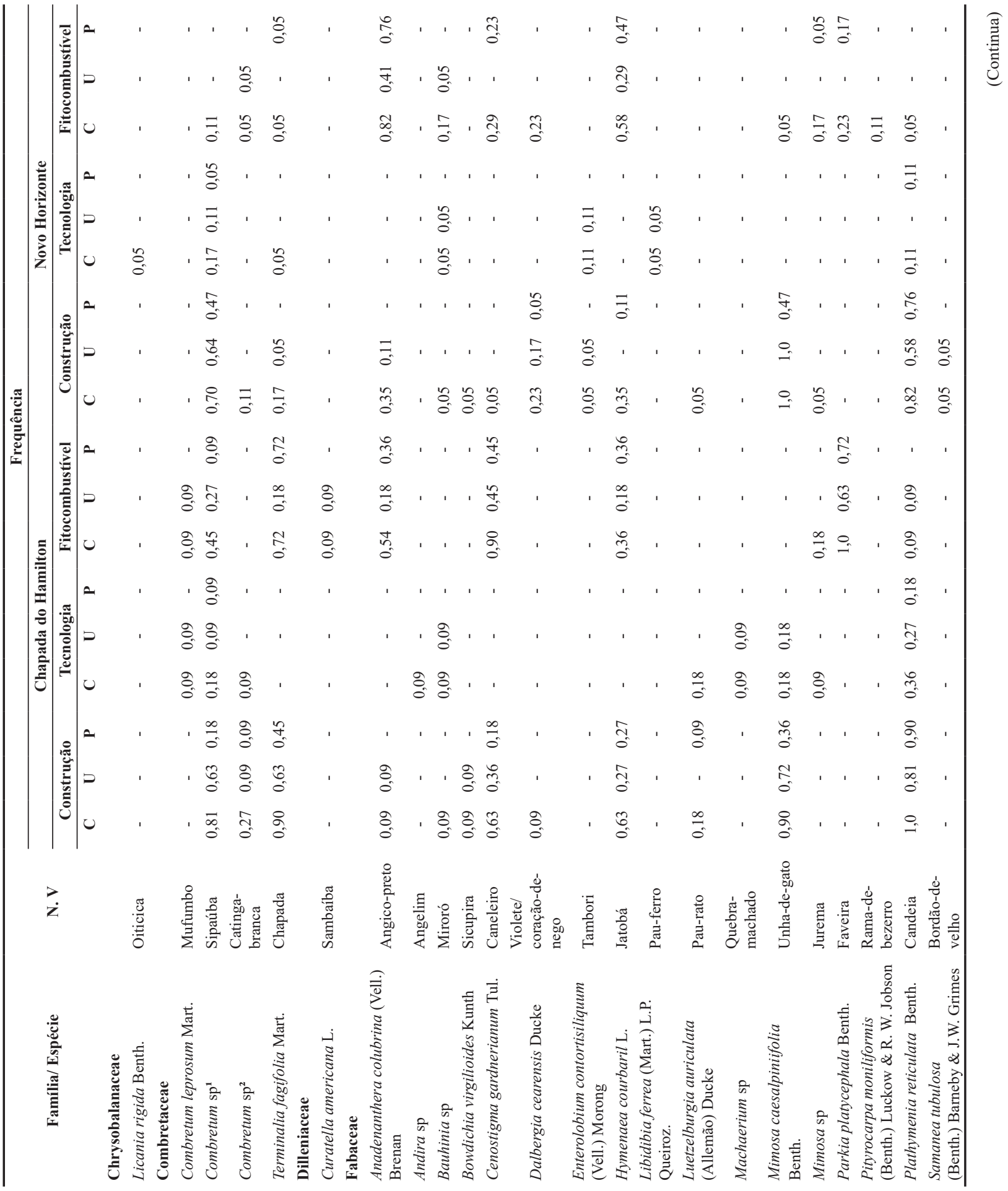




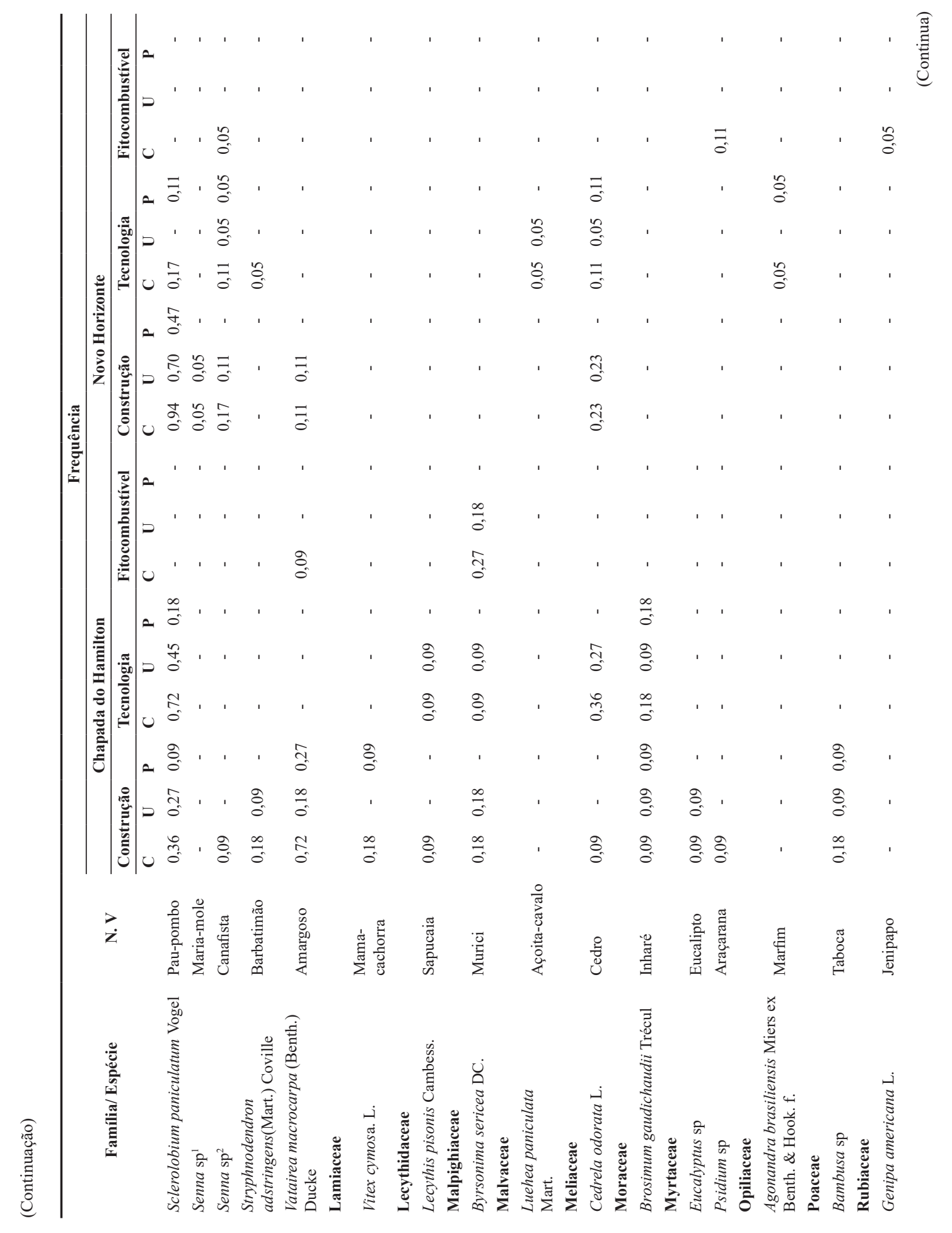




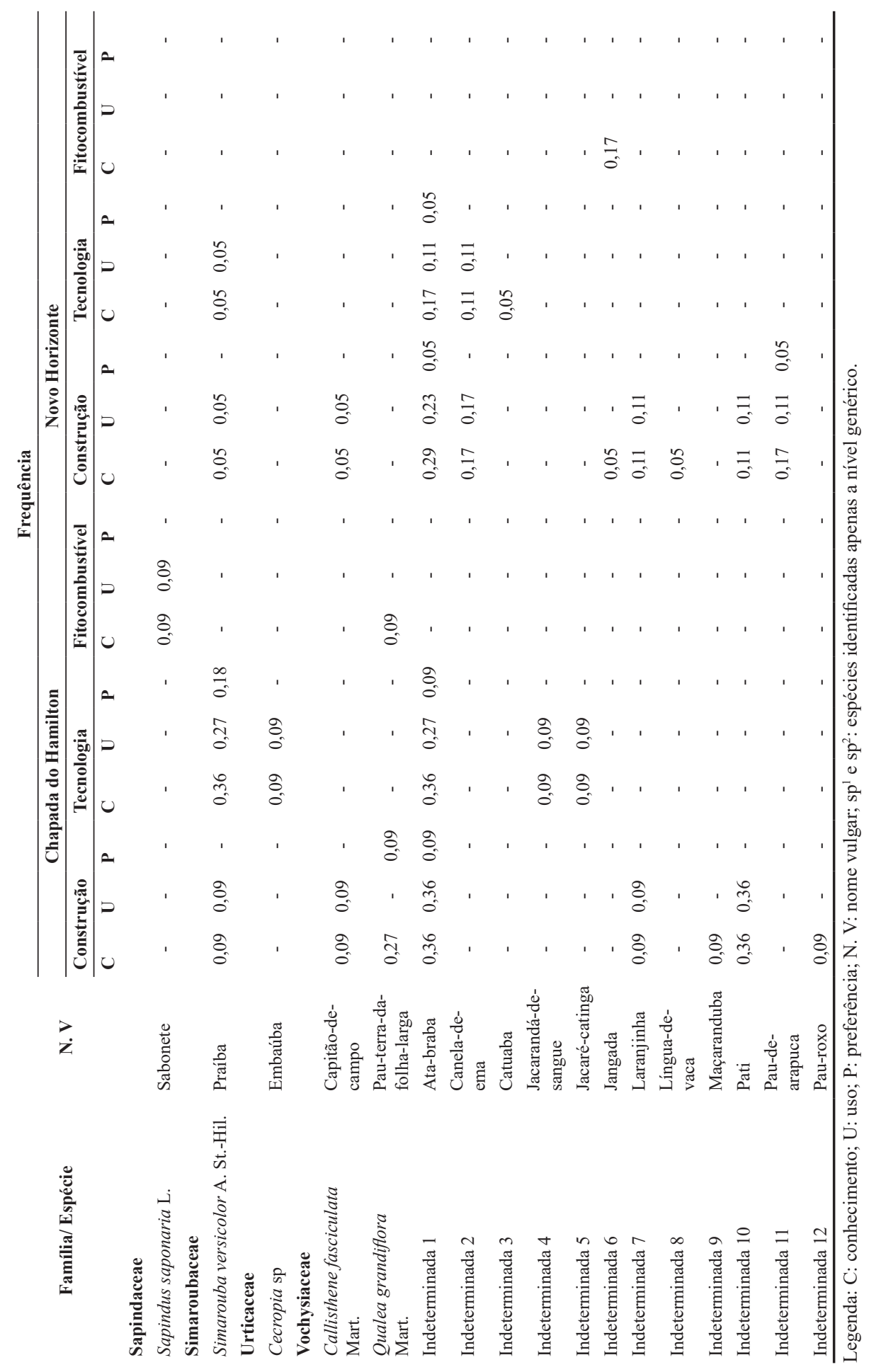


Em relação à quantidade de espécies conhecidas, usadas e preferidas, pode-se observar que Chapada do Hamilton apresentou quantidade maior de espécies citadas, sendo 44 conhecidas, 30 usadas e 20 preferidas, em relação à comunidade Novo Horizonte, que apresentou 42 conhecidas, 30 usadas e 11 preferidas. Não foram encontradas diferenças estatísticas significativas entre as espécies conheci$\operatorname{das}\left(\chi^{2}=0,047 ; \mathrm{p}=0,9141\right)$, usadas $\left(\chi^{2}=0 ; \mathrm{p}=1\right)$ e preferidas $\left(\chi^{2}=2,613 ; \mathrm{p}=0,1508\right)$ para construção entre as comunidades (Figura 7).

Os moradores das comunidades citaram menor número de espécies como preferidas de acordo com determinadas características de interesse, que variaram de acordo com o uso específico, como no caso da categoria construção, em que os usos específicos estão agregados em dois grandes grupos, ou seja, geralmente espécies que são preferidas para uso em telhados não são preferidas para uso em contato com o solo, devido principalmente à resistência à deterioração no solo. As espécies mais resistentes à "ação do tempo" são classificadas como "madeiras do chão", já as espécies menos resistentes ao contato com a terra são consideradas "madeiras do ar", consoante Lima et al. (2011). Inclusas na categoria construção, os especialistas dividiram as espécies em dois grupos distintos, (1) madeiras do ar, que são usadas para construção de cumeeira, caibro e ripa, e (2) madeiras do chão, empregadas para a construção de esteio, finco e vara. Os critérios usados para classificação desses dois grupos baseiam-se na resistência da madeira. O percentual de citação das características de interesse está elencado na Tabela 2 , em que a durabilidade da madeira apresentou maior frequência de citação pelos moradores na categoria construção.
TABELA 2 - Percentual de citação das características de interesse em plantas utilizadas para construção nas comunidades Chapada do Hamilton e Novo Horizonte, Angical do Piauí/PI.

\begin{tabular}{lccc}
\hline Motivos da preferência & F.C. (\%) & $\begin{array}{c}\text { Chapada do } \\
\text { Hamilton }\end{array}$ & $\begin{array}{c}\text { Novo } \\
\text { Horizonte }\end{array}$ \\
\hline Durabilidade & 49,15 & 11 & 18 \\
Resistência às pragas & 18,64 & 5 & 6 \\
Disponibilidade & 15,25 & 3 & 6 \\
Formato & 10,17 & 2 & 4 \\
Resistência à deformação & 6,78 & 3 & 1 \\
\hline
\end{tabular}

Legenda: F.C. - Frequência de Citação (\%).

Dentre as espécies citadas como preferidas, estão as que tiveram valores de uso na categoria construção em ambas as comunidades, como, por exemplo, M. caesalpiniifolia (Tabela 3).

TABELA 3 - Valores de uso de espécies preferidas para categoria construção nas comunidades Chapada do Hamilton e Novo Horizonte, Angical do Piauí/PI.

\begin{tabular}{lcc}
\hline \multirow{2}{*}{ Espécie } & \multicolumn{2}{c}{ Valor de Uso } \\
\cline { 2 - 3 } & $\begin{array}{c}\text { Chapada do } \\
\text { Hamilton }\end{array}$ & $\begin{array}{c}\text { Novo } \\
\text { Horizonte }\end{array}$ \\
\hline Aspidosperma sp & 1,0 & 0,29 \\
Cenostigma gardnerianum Tul. & 1,0 & 0,05 \\
Combretum sp & 2,0 & 2,52 \\
Handroanthus impetiginosus (Mart. & 1,45 & 1,64 \\
ex DC.) Mattos & 1,09 & 0,41 \\
Hymenaea courbaril L . & 2,0 & 4,2 \\
Mimosa caesalpiniifolia Benth. & 1,0 & 2,35 \\
Myracrodruon urundeuva Allemão & 2,9 & 2,05 \\
Plathymenia reticulata Benth. & 0,36 & 2,29 \\
Sclerolobium paniculatum Vogel & 3,0 & 0,23 \\
Terminalia fagifolia Mart. & 1,18 & 0,23 \\
Vatairea macrocarpa (Benth.) Ducke & & \\
\hline
\end{tabular}

O fato de algumas espécies apresentarem valores de uso elevados em uma comunidade e valores baixos em outra pode ser explicado, segundo os entrevistados, pela baixa frequência ou até mesmo a ausência da espécie nas proximidades 
das comunidades, como é o caso da Terminalia fagifolia. Mart. e Cenostigma gardnerianum Tul., que, segundo os atores sociais da pesquisa, ocorrem em locais de terra mais seca, sendo mais comuns nas proximidades da Chapada do Hamilton. Tal fato tem sido confirmado em alguns estudos que testam a hipótese da aparência ecológica, que relaciona o uso com a disponibilidade do recurso na área, como no estudo de Tunholi et al. (2013), em que 19 espécies apresentaram correlação positiva entre os parâmetros fitossociológicos e o valor de uso.

Ressaltamos que em algumas espécies citadas na presente pesquisa tal fato não foi certificado, como, por exemplo, em Handroanthus impetiginosus (Mart. ex DC.) Mattos, que não ocorre na comunidade Chapada do Hamilton, e em Plathymenia reticulata Benth., que não ocorre nas proximidades da comunidade Novo Horizonte e, mesmo assim, apresentam altos valores de uso em ambas as comunidades. No caso de Sclerolobium paniculatum Vogel, ocorre exatamente o contrário, pois, segundo moradores, ela não ocorre nas proximidades da comunidade Novo Horizonte e, mesmo assim, apresenta alto valor de uso na comunidade e baixo valor de uso em Chapada do Hamilton, onde é espécie frequente, de acordo com os entrevistados. Vale a pena salientar, então, que podem existir outros fatores além da frequência que influenciam no conhecimento e no uso das espécies em questão e que o valor de uso é altamente influenciado pelo número de pessoas que citam muitos usos de uma espécie, ou seja, uma planta pode ser altamente cotada, mesmo que seus muitos usos sejam citados por um pequeno número de pessoas, não fazendo, portanto, distinção entre o uso passado, o conhecimento e o uso efetivo das espécies (Albuquerque et al., 2006).

Os padrões de coleta de madeira para construção são potencialmente danosos para as comunidades vegetais, pois os moradores afirmam que, além de colher madeira viva, a parte da planta mais utilizada para tal categoria é o tronco. Esse fato está de acordo com o encontrado no estudo de Medeiros et al. (2011), em que os moradores não utilizam madeira seca para a referida categoria, pois apresenta menor durabilidade e resistência. Assim, é importante ressaltar que a madeira utilizada na categoria construção apresenta maior vida útil, sendo necessário maior tempo de reposição, acarretando assim em menor impacto relativo nas comunidades vegetais. Essa constatação também está presente no estudo de Medeiros et al. (2011).

\subsubsection{Tecnologia}

Essa categoria é bem abrangente nas comunidades, abarcando usos como confecção de cabos de ferramentas e jiraus, que são armações de madeira para colocação de panelas e outros, até alguns móveis (Figura 4).

Em relação às espécies conhecidas, usadas e preferidas na categoria tecnologia, verificou-se que a comunidade Chapada do Hamilton apresenta 29 espécies conhecidas, 23 usadas e 10 preferidas, enquanto Novo Horizonte apresenta 24 espécies conhecidas, 16 usadas e 11 preferidas (Figura 6).

Não houve diferença estatística significativa entre a quantidade de plantas conhecidas $\left(\chi^{2}=\right.$ $0,472 ; \mathrm{p}=0,5827)$, usadas $\left(\chi^{2}=1,256 ; \mathrm{p}=0,3367\right)$ e preferidas $\left(\chi^{2}=0,048 ; p=1\right)$ na categoria tecnologia entre as comunidades estudadas (Figura 7).

Os entrevistados selecionaram características que tornam uma espécie preferida dentro da categoria. Na Tabela 4, estão listadas as características citadas pelos moradores das comunidades, sendo que as características mais citadas para a referida categoria foram resistência $(42,31 \%)$ e peso $(23,08 \%)$. 


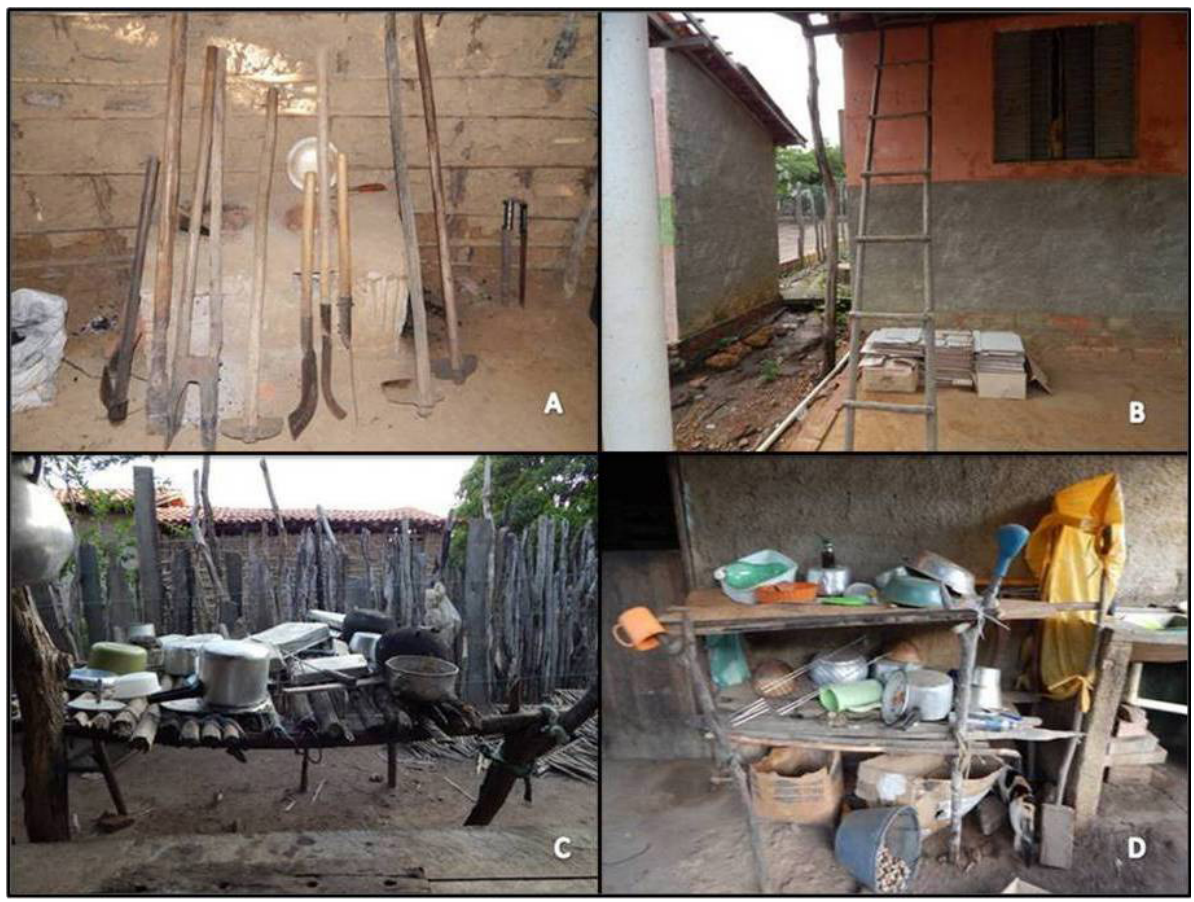

FIGURA 4 - Usos madeireiros na categoria tecnologia nas comunidades Chapada do Hamilton e Novo Horizonte, Angical do Piauí/PI: A - Cabos de ferramentas; B - Escada; C e D - "Jiraus". FONTE: arquivo pessoal.

TABELA 4 - Características de interesse na categoria tecnologia nas comunidades Chapada do Hamilton e Novo Horizonte, Angical do Piauí/PI.

\begin{tabular}{lccc}
\hline Motivos da Preferência & F.C. & $\begin{array}{c}\text { Chapada do } \\
\text { Hamilton }\end{array}$ & $\begin{array}{c}\text { Novo } \\
\text { Horizonte }\end{array}$ \\
\hline Resistência & 42,31 & 6 & 5 \\
Peso & 23,08 & - & 6 \\
Formato & 15,38 & 1 & 3 \\
Durabilidade & 7,69 & - & 2 \\
Ajustabilidade & 7,69 & 1 & 1 \\
Disponibilidade & 3,85 & - & 1 \\
\hline
\end{tabular}

Legenda: F.C. - Frequência de Citação (\%).

Os padrões de coleta de plantas para a categoria tecnologia se caracterizam pela busca de madeira "verde", ou seja, ainda viva para a utilização, como, por exemplo, para cabo de ferramentas, uso que exige resistência, que por sua vez não é suprida por madeira seca. Segundo Medeiros et al. (2011), esse padrão de coleta de madeira ainda viva se torna destrutivo, além do que a parte da planta exigida para tais fins geralmente é o tronco.

\subsubsection{Fitocombustivel}

Todas as residências visitadas na comunidade Chapada do Hamilton fazem uso de madeira para fornecimento de energia, predominantemente na forma de carvão. Alguns estudos divergem de tal verificação, como no estudo de Nascimento (2013), desenvolvido em assentamento rural na zona de amortecimento da Floresta Nacional do Araripe, no Estado do Ceará, onde predomina a vegetação de cerrado, em que a lenha é o principal fornecedor de 
energia, em detrimento do carvão. A investigação de Badshah et al. (2014), realizada no Paquistão, revelou que $90 \%$ da população necessita da lenha para uso doméstico, principalmente para o preparo dos alimentos; já no estudo de Cavalcanti et al. (2015), realizado na Floresta Nacional do Araripe, foi detectado o uso preferencial de lenha para beneficiamento do óleo de pequi (Caryocar coriaceum Wittm.). Entretanto, Vieira (2014), em seu trabalho desenvolvido em uma comunidade quilombola e num assentamento rural no Piauí, confirma que o carvão é mais utilizado nas comunidades por ele investigadas.

Nenhum entrevistado afirmou que depende unicamente do carvão como fonte de energia, sendo usado também o gás liquefeito de petróleo (GLP). Contudo, Nascimento (2013) verificou que uma parcela da população analisada, $16,66 \%$, depende exclusivamente da energia que provém dos fitocombustíveis. Ramos \& Albuquerque (2012) estudaram duas comunidades rurais da Paraíba, Nordeste do Brasil, com vegetação de caatinga, verificaram que a maioria dos entrevistados utiliza lenha em suas casas (88\%) e, destes, $18,2 \%$ contam com este recurso como a única fonte de energia para cozinhar alimentos, enquanto que $81,8 \%$ utilizam a lenha e o gás liquefeito de petróleo (GLP). Medeiros et al. (2012), em seu estudo em área de mata atlântica, e Pérez-Negrón \& Casas (2007), em seus estudos em área do semiárido mexicano, também verificaram que a população usa os fitocombustíveis em associação com o fogão a gás, com o intuito principal de economizar.

Ao serem perguntados sobre a frequência de uso do fogão de barro e do fogão convencional a gás, os moradores afirmaram que fazem uso do fogão convencional quando o tempo de uso é curto, como, por exemplo, para fazer um café ou esquentar uma comida previamente preparada. $\mathrm{O}$ uso do fogão de barro é preferido para cozimentos mais demorados, como feijão, arroz e outros (Figura 5). Ramos \& Albuquerque (2012), em estudo realizado em comunidades rurais no Estado da Paraíba, também levantaram os mesmos dados

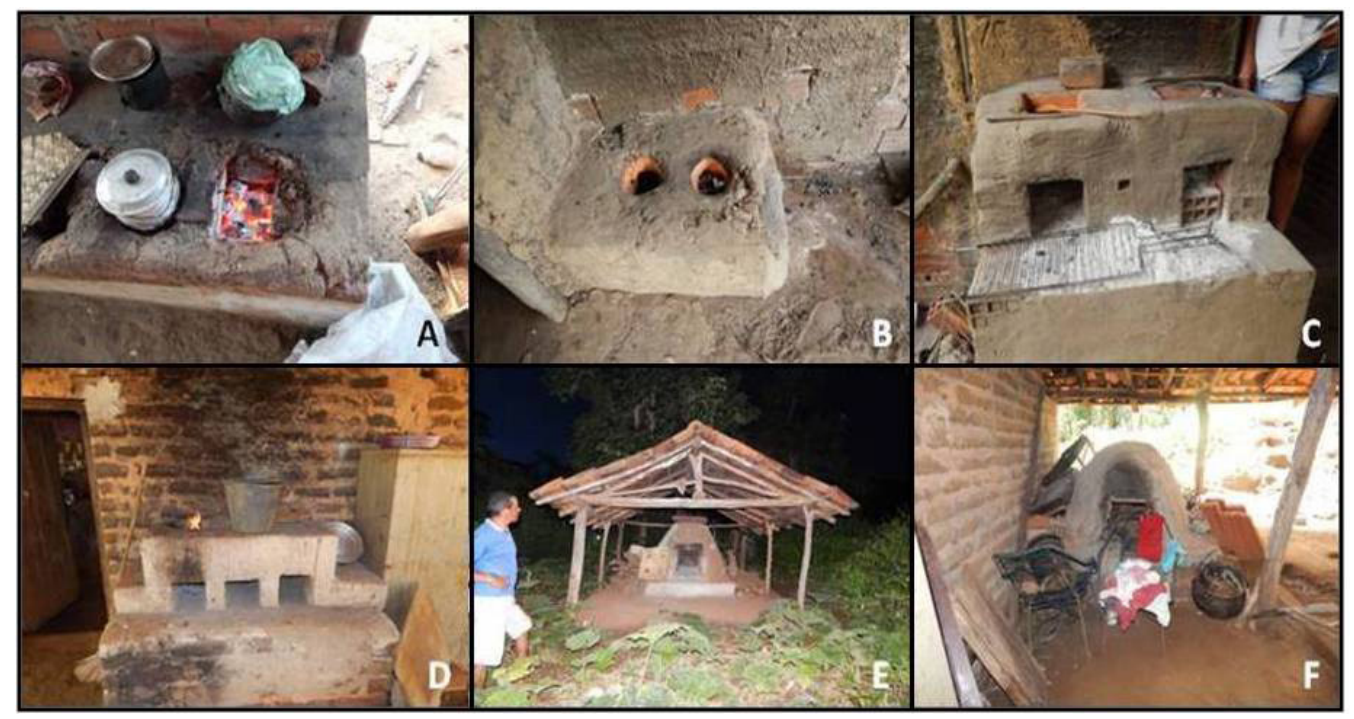

FIGURA 5 - Fogões e fornos de barro à base de carvão vegetal encontrados nas comunidades Chapada do Hamilton e Novo Horizonte, Angical do Piauí/PI. A, B, C e D: Fogões; E e F: Fornos. FONTE: arquivo pessoal. 
referidos para as comunidades rurais no Piauí, em que é dada preferência para o uso do fogão a lenha para cozimentos mais demorados.

Ao serem questionados sobre a proveniência do material utilizado para a fabricação do carvão, os responsáveis pela produção na comunidade Chapada do Hamilton afirmaram que todo o material provém da queima das roças na comunidade. Os padrões de coleta, dessa forma, se tornam menos destrutivos, como afirmam Medeiros et al. (2011), em seu estudo em área de Floresta Atlântica no Estado de Pernambuco, pois, ao se coletar material seco (não vivo), as partes das plantas que são utilizadas para fabricação do carvão, como galhos secos, tornam os impactos da utilização de vegetais para fitocombustível menos prejudiciais.

O carvão é produzido nas comunidades estudadas em estruturas denominadas "caieiras", como pode ser visto na Figura 6.

Ainda segundo os responsáveis, o melhor período para fabricação do carvão é a estação chuvosa, compreendida entre os meses de janeiro e maio. A explicação dos entrevistados para essa preferência está no fato de que a terra molhada favorece o processo, aumentando a produção, quando comparada com a fabricação do carvão em terra seca, na qual, de acordo com eles, a queima do carvão na caieira é mais intensa e acaba desintegrando o carvão. Os estudos de Ramos \& Albuquerque (2012) e Medeiros et al. (2012) divergem dessa preferência pelo período chuvoso para produção de fitocombustível (lenha), pois, em virtude de ser utilizada a lenha, a população prefere o período seco para a coleta. Isso se deve, principalmente, à preferência da população pela lenha seca para a produção de energia e pela facilidade de coleta na estação seca. Contudo, Nascimento (2013) visualizou que, apesar de muitos moradores preferirem coletar na estação seca, a coleta de lenha é realizada durante todo o ano, muito provavelmente devido às restrições de coleta estabelecidas na área de estudo.

No que diz respeito à quantidade de espécies conhecidas, usadas e preferidas para fitocombustíveis nas comunidades, pode se observar que a comunidade Chapada do Hamilton apresentou acervo de 17 plantas conhecidas, 14 usadas e oito

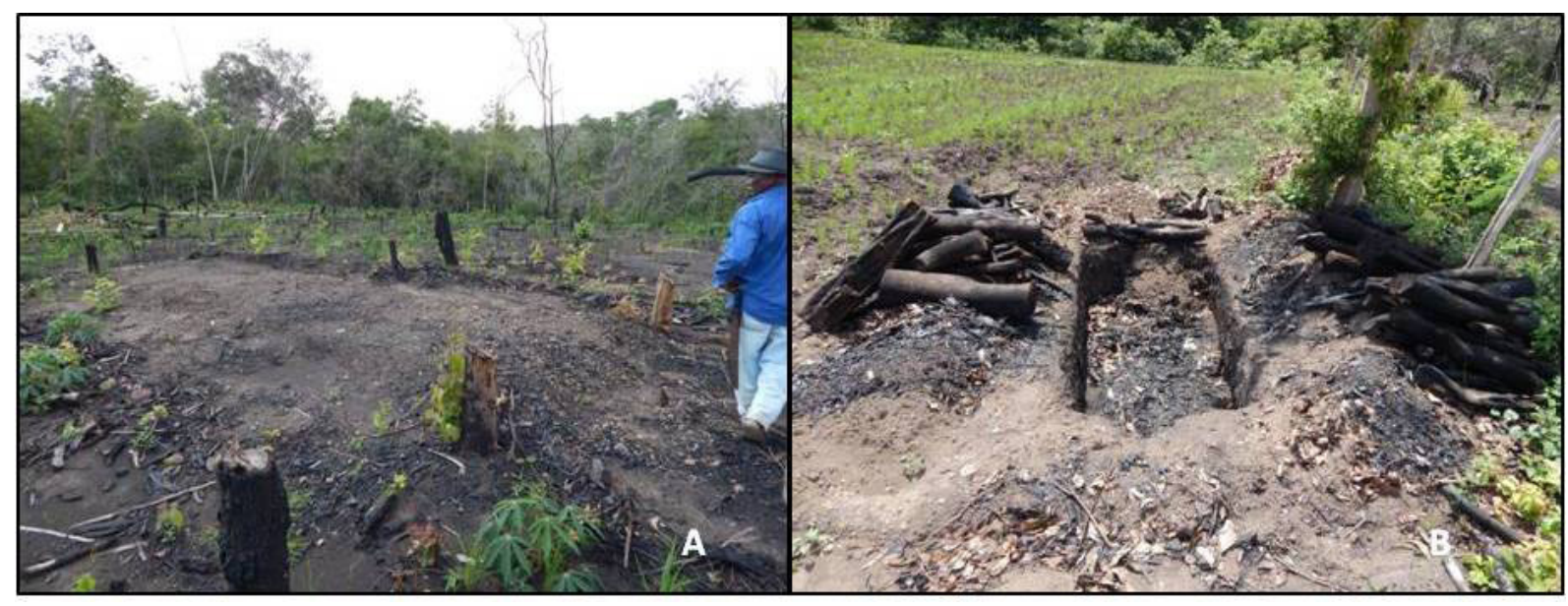

FIGURA 6 - Local de fabricação do carvão nas comunidades Chapada do Hamilton e Novo Horizonte, Angical do Piauí/PI. A: Caieira fechada; B: Caieira aberta.

FONTE: arquivo pessoal. 
preferidas, e a comunidade Novo Horizonte registrou 20 espécies conhecidas, cinco usadas e seis preferidas. Não houve diferenças estatísticas significativas entre o número de espécies conhecidas $\left(\chi^{2}=0,243 ; \mathrm{p}=0,7423\right)$, utilizadas $\left(\chi^{2}=4,263 ; \mathrm{p}=\right.$ $0,0665)$ e preferidas $\left(\chi^{2}=0,286 ; p=0,7893\right)$ para fitocombustível entre as comunidades (Figura 7). No estudo de Vieira (2014), houve diferença estatística significativa entre o número de espécies conhecidas e preferidas entre as comunidades, mostrando que uma comunidade apresenta conhecimento mais especializado sobre as espécies vegetais utilizadas como combustível; no entanto, o número de espécies utilizadas não variou significativamente entre as duas comunidades. Apesar de não haver diferenças estatísticas significativas, a comunidade Novo
Horizonte apresentou menor número de espécies utilizadas como fitocombustível e isso se deve ao fato de que a referida comunidade faz uso, preferencialmente, da casca do coco babaçu (Attalea speciosa Mart. ex Spreng.) como fonte de energia.

Os moradores de ambas as comunidades conhecem diversas espécies vegetais que podem fornecer energia, mas elegem um grupo menor de plantas como sendo as mais eficientes para essa tarefa, ditas plantas preferidas. Com as entrevistas, foi possível elencar os critérios que levam os moradores a elencar um grupo mais restrito de plantas como preferidas na referida categoria, como pode ser visto na Tabela 5 , em que o poder calorífico $(32,14 \%)$ e a durabilidade da brasa (25\%) apresentaram maiores percentuais de citação para a categoria.

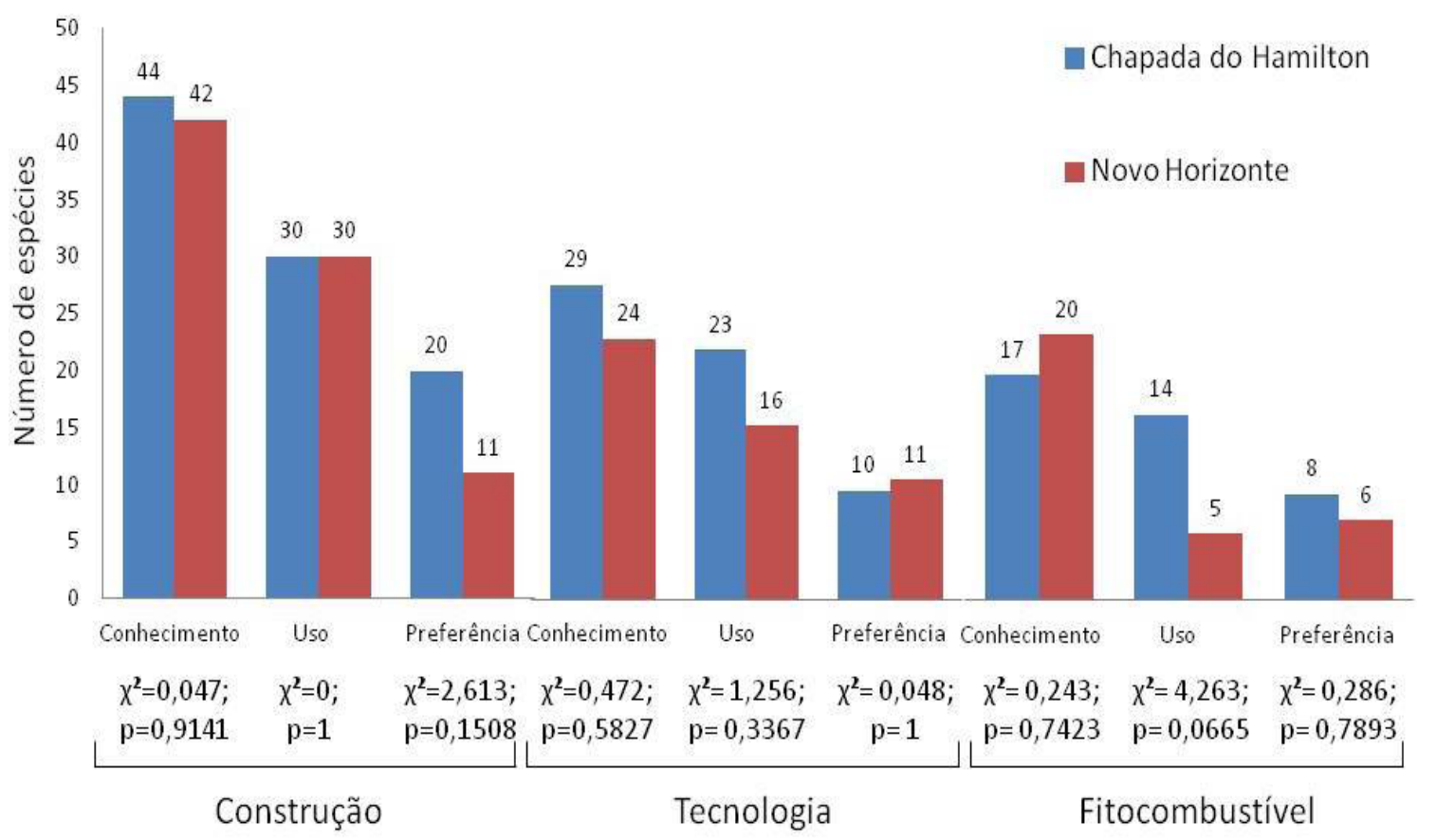

FIGURA 7 - Conhecimento, uso e preferência nas categorias construção, tecnologia e fitocombustível nas comunidades Chapada do Hamilton e Novo Horizonte, Angical do Piauí/PI.

FONTE: dados da pesquisa. 
TABELA 5 - Percentual de citação das características de interesse em plantas utilizadas como fitocombustível nas comunidades Chapada do Hamilton e Novo Horizonte, Angical do Piauí/PI..

\begin{tabular}{lccc}
\hline Motivos da preferência & F.C. & $\begin{array}{c}\text { Chapada do } \\
\text { Hamilton }\end{array}$ & $\begin{array}{c}\text { Novo } \\
\text { Horizonte }\end{array}$ \\
\hline Poder calorífico & 32,14 & 6 & 3 \\
Durabilidade da brasa & 25,00 & 4 & 3 \\
Firmeza & 17,86 & 3 & 2 \\
Não estalar & 10,71 & 3 & - \\
Pouca cinza & 7,14 & 2 & - \\
Pouca fumaça & 7,14 & - & 2 \\
\hline
\end{tabular}

Legenda: F.C. - Frequência de Citação (\%).

FONTE: dados da pesquisa.

Estudos como o de Badshah et al. (2014), realizado no Paquistão, e Specht et al. (2015), realizado em área de Floresta Atlântica em Pernambuco, concordam com o poder calorífico como característica principal na escolha de uma espécie como preferida. Outros estudos, como o de Nascimento (2013) e Vieira (2014), concordam que a característica principal para escolha de espécie preferida é a durabilidade da brasa.

As espécies citadas como preferidas para fitocombustível nas duas comunidades também apresentaram elevados valores de uso, conforme observado na Tabela 6, em que espécies como Anadenanthera sp. (angico-preto), Hymenaea sp. (jatobá) e Parkia platycephala Benth (faveira) apresentaram elevados valores de uso.

Pode-se confirmar, com o cálculo do valor de uso (VU), que as espécies com citações de preferência na categoria fitocombustível também apresentam elevado valor de uso, o que sugere que as plantas citadas como preferidas são as mais lembradas e importantes para as comunidades.
TABELA 6 - Valores de uso das espécies citadas como preferidas na categoria fitocombustível nas comunidades Chapada do Hamilton e Novo Horizonte, Angical do Piauí/PI.

\begin{tabular}{lcc}
\hline Espécie & $\begin{array}{c}\text { Chapada do } \\
\text { Hamilton }\end{array}$ & $\begin{array}{c}\text { Novo } \\
\text { Horizonte }\end{array}$ \\
\hline Anacardium occidentale L. & 0,09 & - \\
Anadenanthera sp & 0,72 & 0,82 \\
Cenostigma gardnerianum Tul. & 0,81 & 0,29 \\
Combretum sp & 0,72 & 0,11 \\
Hymenaea sp & 0,72 & 0,58 \\
Mimosa sp & 0,27 & 0,17 \\
Parkia platycephala Benth. & 1,0 & 0,23 \\
Terminalia fagifolia Mart. & 0,72 & 0,05 \\
\hline
\end{tabular}

\section{Considerações finais}

Pode-se verificar que a categoria construção apresentou maior quantidade de espécies conhecidas em relação às categorias tecnologia e fitocombustível. Tal fato pode indicar que a pressão de uso pode estar mais distribuída nas espécies, em virtude, também, da elevada quantidade de espécies preferidas. Vale a pena salientar que espécies com alta versatilidade, ou seja, que são bem utilizadas em mais de uma categoria de uso madeireiro, como, por exemplo, Myracrodruon urundeuva Allemão (aroeira), Sclerolobium paniculatum Vogel (pau-pombo), Simarouba versicolor A. St.-Hil. (praíba), Plathymenia reticulata Benth. (candeia), Handroanthus impetiginosus (Mart. ex DC.) Mattos (pau-d'arco-roxo), Terminalia fagifolia Mart. (chapadeiro), Combretum sp (sipaúba), Hymenaea sp (jatobá) e Mimosa caesalpiniifolia Benth. (unha-de-gato), estejam sofrendo maior pressão de uso, sugerindo-se, portanto, estudo sobre estrutura populacional destas espécies, a fim de indicá-las como prioridade em estratégias futuras de conservação.

Consideramos como categoria de uso madeireiro mais importante para as comunidades a cate- 
goria construção, devido ao amplo conhecimento de espécies e ao uso generalizado em ambas as comunidades. Devido aos padrões de coleta e de uso da madeira na categoria construção, que dá preferência à madeira viva, consideramos também a categoria como prioritária do ponto de vista da conservação, visto que a categoria fitocombustível apresenta padrões de coleta menos destrutivos e a categoria tecnologia não apresenta amplo conhecimento, sendo também registrada em uma frequência

\section{Referências}

Aguiar, R. B.; Gomes, J. R. C. Projeto cadastro de fontes de abastecimento por água subterrânea, estado do Piaui: diagnóstico do município de Angical do Piauí. Fortaleza: CPRM - Serviço Geológico do Brasil, 2004. 20 p.

Albuquerque, U. P.; Lucena, R. F.; Monteiro, J. M.; Florentino, A. T.; Almeida, C. D. F. C. Evaluating two quantitative ethnobotanical techniques. Ethnobotany Research and Applications, 4, 51-60, 2006. Disponível em: <http://hdl. handle.net/10125/237>.

Albuquerque, U. P.; Lucena, R. F. P.; Cunha, L, V. F. C.; Alves, R. R. N. Methods and Techniques in Ethnobiology and Ethnoecology. New York: Humana Press, 2014. 476 p. Disponível em: $<$ http://dx.doi.org/10.1007/978-1-46148636-7>.

Almeida, C. F. C. B. R.; Albuquerque, U. P. Uso e conservação de plantas e animais medicinais no Estado do Pernambuco (Nordeste do Brasil): um estudo de caso. Interciência, 27(6), 276-285, 2002.

Ayres, M.; Ayres, J. R.; Ayres, D. L.; Santos, A. S. BioEstat 5.0 - aplicações nas áreas de ciências biológicas e médicas. Belém: Sociedade Civil Mamirauá, 2007. 364 p. Disponível em: <http://dv.ict.unesp.br/ivan/downloads/ Bioestat_5*Manual-BioEstat_5.pdf >.

Badshah, L.; Hussain, F.; Sher, Z.; Burni, T. Harvesting and consumption of fuel and timber wood in rural area of district Tank, Pakistan. Pakistan Journal of Botany, 46(5), 1719-1724, 2014. Disponível em: <http://www.pakbs.org/ pjbot/PDFs/46(5)/23.pdf>. menor nas residências, comparativamente com as outras categorias.

Por fim, este estudo fornece dados importantes acerca do conhecimento, padrões de coleta e utilização de espécies vegetais do bioma Cerrado para fins madeireiros por populações rurais no estado do Piauí, incrementando e valorizando o conhecimento etnobotânico e fornecendo subsídios para a adoção de alternativas de manejo que levem em consideração as especificidades das populações locais.

Barbosa, A. R. Os humanos e os répteis da mata: uma abordagem etnoecológica de São José da Mata - Paraíba. João Pessoa, Dissertação (Mestrado em Desenvolvimento e Meio Ambiente) - Universidade Federal da Paraíba, 2007.

Bernard, H. R. Research in cultural anthropology. Sage. Newbury Park, CA, EEUU. 1988. 520 p.

Carvalho, F. A.; Rodrigues, V. H. P.; Kilca, R. V.; Siqueira, A. S.; Araújo, G. M.; Schiavini, I. "Composição florística, riqueza e diversidade de um cerrado sensu stricto no sudeste do Estado de Goiás." Bioscience jornal, 24(4), 2008. Disponível em: <http://www.seer.ufu.br/index.php/ biosciencejournal/article/viewArticle/6769>.

Cavalcanti, M. C. B. T.; Ramos, M. A.; Araújo, E. L.; Albuquerque, U. P. Implications from the use of non-timber forest products on the consumption of wood as a fuel source in human-dominated semiarid landscapes. Environmental Management, 56, 389-401, 2015. Disponível em: <http:// dx.doi.org/10.1007/s00267-015-0510-4>.

Chaves, E. M. F.; Chaves, E. B. F.; Servio Junior, E. M.; Barros, R. F. M. Conhecimento tradicional: a cultura das cercas de madeira no Piauí, Nordeste do Brasil. Etnobiología, 12, 31-43, 2014. Disponível em: <http://asociacionetnobiologica.org.mx/aem/wp-content/uploads/revista12-1/ Etnobiologia\%2012-1.pdf>.

Conselho Nacional de Saúde. Resolução $n^{\circ} 466$, de 12 de Dezembro de 2012. Estabelece as diretrizes e normas brasileiras regulamentadoras de pesquisas envolvendo seres humanos. Diário Oficial da União, n. 12, quinta-feira, 13 
de junho de 2013, Seção 1, Pág. 59. Disponível em: <http:// conselho.saude.gov.br/resolucoes/2012/Reso466.pdf > . Acesso em: 04 jan. 2015.

Depro, B. M.; Murray, B. C.; Alig, R. J.; Shanks, A. Public land, timber harvests, and climate mitigation: quantifying carbon sequestration potential on US public timberlands. Forest Ecology and Management, 255(3), 1122-1134, 2008. doi: 10.1016/j.foreco.2007.10.036.

Fidalgo, O.; Bononi, V. L. R. Técnicas de coleta, preservação e herborização de material botânico. São Paulo: Instituto Botânica, 1989. 62 p.

Garay, I. E. G.; Becker, B. K. As dimensões humanas da biodiversidade: o desafio de novas relações sociedade-natureza no século XXI. Petrópolis, RJ: Vozes, 2006

Gaugris, J. Y.; Van Rooyen, M. W. Questionnaires do not work! A comparison of methods used to evaluate the structure of buildings and wood used in rural households, South Africa. Ethnobotany Research and Applications, 4, 119-131, 2006. Disponível em: <http://scholarspace.manoa. hawaii.edu/bitstream/handle/10125/244/I1547-3465-04119.pdf? sequence $=4>$.

Guariguata, M. R.; Cronkleton, P.; Shanley, P.; Taylor, P. L. The compatibility of timber and non-timber forest product extraction and management. Forest Ecology and Management, 256(7), 1477-1481, 2008. doi: 10.1016/j. foreco.2008.03.038.

Guariguata, M. R.; García-Fernández, C.; Sheil, D.; Nasi, R.; Herrero-Jáuregui, C.; Cronkleton, P.; Ingram, V. Compatibility of timber and non-timber forest product management in natural tropical forests: perspectives, challenges, and opportunities. Forest Ecology and Management, 259(3), 237-245, 2010. doi: 10.1016/j.foreco.2009.11.013.

IBGE. Instituto Brasileiro de Geografia e Estatística. Censo 2010. Disponível em: <http://www.censo2010.ibge.gov.br/ pt/>. Acesso em: 29 ago. 2014.

Kristensen, M. K.; Lykke, A. M. Informant-based valuation of use and conservation preferences of savanna trees in Burkina Faso. Economic Botany, 57, 203-217, 2003. doi: 10.1663/0013-0001(2003)057\%5B0203:IVOUAC\% 5D2.0.CO;2.

Leefers, L. A.; Vasievich, J. M. Timber resources and factors affecting timber availability and sustainability for Kinross, Michigan. Kinross Project, 2, 2010. Disponível em: < http://michiganwoodbiofuels.org/sites/default/files/ Attachment \%201_Feedstock\%20Inventory\%20report v3_01072011.pdf>.

Lima, J. S.; Oliveira, D. M.; Júnior, J. E. N.; Mann, R. S.; Gomes, L. J. Saberes e uso da flora madeireira por especialistas populares do agreste de Sergipe. Sitientibus Série Ciências Biológicas, 11(2), 239-53, 2011. doi: 10.13102/scb73.

Lucena, R. F. P.; Farias, D. C.; Carvalho, Nunes, T. K.; Lucena, C. M.; Vasconcelos Neto, C. F. A.; Albuquerque, U. P. Conhecimento tradicional de Myracrodruon Urundeuva Allemão por comunidades tradicionais no semiárido do Nordeste do Brasil. Sitientibus, Série Ciências Biológicas, 11, 255-264, 2011. Disponível em: <http://pkp.uefs.br/ojs/ index.php/sitientibusBiologia/article/viewFile/109/146>.

Medeiros, P. M.; Silva, T. C.; Almeida, A. L. S.; Albuquerque, U. P. Pressure indicators of wood resource use in an Atlantic Forest area, Northeastern Brazil. Environmental Management, 47, 410-424, 2011. doi: 10.1007/s00267011-9618-3.

Medeiros, P. M.; Silva, T. C.; Almeida, A. L. S.; Albuquerque, U. P . Socio-economic predictors of domestic wood use in an Atlantic forest area (north-east Brazil): a tool for directing conservation efforts. International Journal of Sustainable Development and World Ecology, 19, 189-195, 2012. doi: 10.1080/13504509.2011.614288.

Medeiros, P. M.; Soldati, G. T.; Alencar, N. L.; Vandebroek, I.; Pieroni, A.; Hanazaki, N.; Albuquerque, U. P. "The use of medicinal plants by migrant people: adaptation, maintenance, and replacement." Evidence-Based Complementary and Alternative Medicine, 2012 (2011). doi: 10.1155/2012/807452.

Missouri Botanical Garden (MOBOT). Tropicos. Disponível em: <http://tropicos.org/Home.aspx>. Acesso em: 01 jun. 2016.

Mori, S. A.; Silva, A. M.; Lisboa G.; Coradim, L. Manual de manejo do herbário fanerogâmico. 2. ed. CEPLAC: Ilhéus, 1989. 104p.

Nascimento, L. G. S. Uso doméstico de lenha na Floresta Nacional do Araripe: como as restrições legais de acesso a este recurso influenciam os padrões de coleta e as preferências locais da população? Recife, Dissertação (Mestrado em Ecologia) - Universidade Federal Rural de Pernambuco, 2013. 
Nasi, R.; Billand, A.; Van Vliet, N. Managing for timber and biodiversity in the Congo Basin. Forest Ecology and Management, 268, 103-111, 2012. doi: 10.1016/j. foreco.2011.04.005.

Nelson, R.; Ranson, K. J.; Sun, G.; Kimes, D. S.; Kharuk, V.; Montesano, P. Estimating siberian timber volume using MODIS and ICESat/GLAS. Remote Sensing of Environment, 113(3), 691-701, 2009. doi: 10.1016/j. rse.2008.11.010.

Pérez-Négron, E.; Casas, A. Use, extraction rates and spatial availability of plant resources in the Tehuácan-Cuicatlán Valley, Mexico: The Case of Santiago Quiotepec,Oaxaca. Journal of Arid Environments, 70, 356-379, 2007. doi: 10.1016/j.jaridenv.2006.12.016.

Phillips, O.; Gentry, A.H. The usefull plants of Tambopata, Peru: I. Statistical hypothesis tests with a new quantitative technique. Economic Botany, 47, 15-32. 1993. doi: 10.1007/ BF02862203.

Pinto, J. R. R., Lenza, E.; Pinto, A. D. S. Composição florística e estrutura da vegetação arbustivo-arbórea em um cerrado rupestre, Cocalzinho de Goiás, Goiás. Revista Brasileira de Botânica, 32(1), 1-10. 2009. doi: 10.1590/ S0100-84042009000100002.

Pulhin, J. M.; Dressler, W. H. People, power and timber: the politics of community-based forest management. Journal of Environmental Management, 91(1), 206-214, 2009. doi: 10.1016/j.jenvman.2009.08.007.

Ramos, M.A.; Albuquerque, U. P. The domestic use of firewood in rural communities of the Caatinga: how seasonality interferes with patterns of firewood collection. Biomass and Bioenergy, 39, 147-158, 2012. doi: 10.1016/j. biombioe.2012.01.003.

Ramos M. A.; Medeiros P. M.; Albuquerque U. P. Métodos e técnicas aplicados a estudos etnobotânicos com recursos madeireiros. In: Albuquerque, U. P. A.; Lucena, R. F. P.; Cunha, L, V. F. C. (Orgs.). Métodos e técnicas na pesquisa etnobiológica e etnoecológica. NUPEEA, 2010. p. 329-350.

Ramos, M. A.; Medeiros, P. M.; Almeida, A. L. S; Feliciano, A. L. P.; Albuquerque, U. P. Can wood quality justify local preferences for firewood in an area of Caatinga (dryland) vegetation. Biomass and Bioenergy, 32(6), 503-509, 2008. doi: 10.1016/j.biombioe.2007.11.010.
Robiglio, V.; Lescuyer, G.; Cerutti, P. O. From farmers to loggers: the role of shifting cultivation landscapes in timber production in Cameroon. Small-Scale Forestry, 12(1), 6785, 2013. doi: 10.1007/s11842-012-9205-3.

Rossato, S. C. Uso de plantas por comunidades caiçaras do litoral norte do Estado de São Paulo. São Paulo, Dissertação (Mestrado) - Universidade de São Paulo, 1996.

Samant, S. S.; Dhar, U.; Rawal, R. S. Assessment of fuel resource diversity and utilization patterns in Askot Wildlife Sanctuary in Kumaun Himalaya, India, for conservation and management. Environmental Conservation, 27(1), 5-13, 2000. doi: 10.1017/S0376892900000023.

Silva, M. P.; Barros, R. F. M. Conhecimento tradicional e uso de espécies da caatinga em construções rurais na comunidade Sítio Velho em Assunção do Piauí, Brasil. Educação Ambiental em Ação, 51, 2015. Disponível em: $<\mathrm{http}: / /$ revistaea.org/artigo.php?idartigo=1987>.

Silva, F. R. Y, Molina, J. R., González-Cabán, A., Machuca, M. Á. H. Economic vulnerability of timber resources to forest fires. Journal of Environmental Management, 100, 16-21, 2012. doi: 10.1016/j.jenvman.2011.12.026.

Specht, M. J.; Pinto, S. R. R.; Albuquerque, U. P.; Tabarelli, M.; Melo,F. P. L. Burning biodiversity: fuelwood harvesting causes forest degradation in human-dominated tropical landscapes. Global Ecology and Conservation, 3, 200-209, 2015. doi: 10.1016/j.gecco.2014.12.002.

Tabuti, J. R. S. Important woody plant species, their management and conservation status in Balawoli Sub-county, Uganda. Ethnobotany Research \& Applications, 10, 269286, 2012. Disponível em: $<$ http://journals.sfu.ca/era/index. php/era/article/view/682>.

Tabuti, J. R. S.; Dhillion, S. S.; Lye, K. A. Firewood use in Bulamogi County, Uganda: species selection, harvesting and consumption patterns. Biomass and Bioenergy, 25(6), 581-596, 2003. doi: 10.1016/S0961-9534(03)00052-7.

The Angiosperm Phylogeny Group. An update of the Angiosperm Phylogeny Group classification for the orders and families of flowering plants: APG IV. Botanical Journal of the Linnean Society, 181, 1-20, 2016. doi: 10.1111/ boj.12385.

Tongco, M. A. D. C. Purposive sampling as a tool for informant selection. Ethnobotany Research \& Applications, 5, 147-158, 2007. doi: 10125/227. 
Tunholi, V. P.; Ramos, M. A.; Scariot, A. Availability and use of woody plants in a agrarian reform settlement in the Cerrado of the state of Goiás, Brazil. Brasil. Acta Botanica Brasilica, 27, 604-612. 2013. doi: 10.1590/S010233062013000300018 .

Vieira, F. J. Uso de fitocombustível no semiárido brasileiro: preferências locais e atributos físicos da madeira. Teresina, Tese (Doutorado em Desenvolvimento e Meio Ambiente) - Universidade Federal do Piauí, 2014.
Walters, B. B. Patterns of local wood use and cutting of Philippine mangrove forests. Economic Botany, 59(1), 6676, 2005. doi: 10.1663/0013-0001(2005)059\%5B0066:PO LWUA\%5D2.0.CO;2.

Yang, H.; Nie, Y.; Ji, C. Study on China's timber resource shortage and import structure: natural forest protection program outlook, 1998 to 2008. Forest Products Journal, 60(5), 408-414, 2010. doi: 10.13073/0015-7473-60.5.408. 